\title{
Introductory Remarks on Symposium on Fermentation Waste Disposal
}

\begin{abstract}
Presented before the Division of Microbial Chemistry and Technology, and the Division of Water and Wastes Chemistry, 140th Meeting of the American Chemical Society, Chicago, Illinois, September 1961.
\end{abstract}

In common with most industrial processing industries, the fermentation industries are concerned with waste disposal situations that often become critical. Fermentation wastes usually occur in liquid or solid forms, although some gaseous wastes are also produced. It is worthy of note that, in addition to the problems involved, the disposal of these wastes is particularly interesting to fermentation specialists because waste treatment processes are of ten fermentations. For example, the activated sludge process finds its parallel in submerged fermentation for antibiotics, while trickling filters were used for vinegar manufacture long before they were adapted to waste treatment. On the other hand, continuous fermentations have been used from the beginning for waste treatment, whereas in the manufacture of fermentation products continuous operation is still something of a novelty.

The treatment of wastes arising from the production of antibiotics involves many unusual and troublesome factors. These wastes often have very high $B O D$ values and contain residual antibiotics that may interfere with biological treatment; in addition, the wastes vary widely from hour to hour in strength and quantity.

The papers in this symposium were selected to illustrate effective methods for disposing of liquid and solid pharmaceutical wastes as well as current research directed toward improvement of the methods. The first paper outlines methods of evaluating the strengths of liquid wastes by applying procedures developed in the brewing and alcohol distillation industries; such methods are needed when developing or improving waste treatment programs.

Secondary treatment of liquid wastes from antibiotics production is almost exclusively carried out biologically at the present time. 
Both trickling filters and activated sludge processes are successfully used. The generally recognized disadvantage of the activated sludge process, when shock BOD loadings are handled, is less importont in the fermentation industry where competent fermentation specialists are available to assist in the intelligent operation of these plants. Nevertheless, the problems of operating an activated sludge process with widely fluctuating BOD loads, along with the probable presence of antibiotics and toxic solvents in the wastes, are real. These problems are far less troublesome in a trickling filter plant. This comparison is discussed in one of the papers.

Disposal of settled solids is also considered: at least three methods are currently used by the industry, namely, incineration, anaerobic digestion, and composting. Operational data for the latter two methods are included in the present symposium.

Design of activated sludge units for antibiotics wastes is complicated by the factors previously discussed. Some unusual approaches to the design of the specialized activated sludge units suitable for wastes from antibiotic fermentations are offered in two of the papers.

Unfortunately, good secondary treatment of liquid wastes from the production of pharmaceuticals becomes expensive. This has resulted in a continuing search for different and cheaper disposal techniques. Two such methods that are currently in use are presented here: these are injection into deep geological formations and spraying onto the surface of the ground.

The very diversity of the waste treatment processes used for treating wastes from the manufacture of pharmaceuticals attests to the fact that we do not yet have final answers to the problems involved. Continued, imaginative research and intelligent use of the results by engineers are needed to reduce the cost and increase the effectiveness of these waste treatment processes.

LLOYD L. KEMPE

University of Michigan

Ann Arbor, Michigan 